\title{
Distribution of Bactrocera oleae (Rossi, 1790) throughout the Iberian Peninsula based on a maximum entropy modelling approach
}

\author{
Jacinto Benhadi-Marín ${ }^{1}$ \\ José Alberto Pereira ${ }^{1}$
}

${ }^{1}$ Centro de Investigação de Montanha (CIMO), Instituto Politécnico de Bragança, Campus de Santa Apolónia, Bragança, Portugal

${ }^{2} \mathrm{CIQuiBio}$, Barreiro School of Technology, Polytechnic Institute of Setúbal, Lavradio, Portugal

${ }^{3}$ LEAF, Instituto Superior de Agronomia, Lisbon, Portugal

\section{Correspondence}

Jacinto Benhadi-Marín, Centro de Investigação de Montanha (CIMO), Instituto Politécnico de Bragança, Campus de Santa Apolónia, 5300-253 Bragança, Portugal.

Email: jbenma@ipb.pt

Funding information

FEDER (European Fund for Regional Development), Grant/Award Number: Programme PT2020; Fundação para a Ciência e a Tecnologia, Grant/Award Numbers: PEstOE/AGR/UI0690/2019 - CIMO, POCI01-0145-FEDER-031133

\author{
Sónia A.P. Santos ${ }^{2,3}$
}

Paula Baptista $^{1}$

\section{1 | INTRODUCTION}

The olive tree (Olea europaea L.) cultivation strongly influences the human life across the Mediterranean basin from economic to landscape aspects (Loumou \& Giourga, 2003). The Mediterranean basin encompasses $91.83 \%$ of the world olive harvested area (FAOSTAT, 2019). This region produces and consumes $99 \%$ and $87 \%$ of the world's olive oil respectively. Southwestern Europe (i.e., the Iberian Peninsula housing Portugal and Spain) represents $29.36 \%$ of the olive harvested area within the entire Mediterranean basin (FAOSTAT, 2019).

The olive tree is susceptible to the attack of different insect pests such as Bactrocera oleae (Rossi, 1790) (Diptera), Prays oleae (Bernard, 1788) (Lepidoptera), Saissetia oleae (Olivier, 1791) (Hemiptera), Euphyllura olivina Costa, 1839 (Hemiptera), and 
Phloeotribus scarabaeoides (Bernard, 1788) (Coleoptera) (Haber \& Mifsud, 2007; Haniotakis, 2003). Among them, the olive fruit fly is the most damaging pest across the Mediterranean basin because of direct pulp destruction caused by the larvae development, premature drop of the infested fruits and general reduction in olive oil quality, which may cause a loss up to $40 \%$ of the production (Boccaccio \& Petacchi, 2009; Pereira, Alves, Casal, \& Oliveira, 2004).

Accordingly, monitoring schemes have been implemented by the countries as an informative and predictive-like tool such as the Spanish monitoring web of olive pests "Red DACUS." However, efficient networks of monitoring stations are usually expensive (e.g., in terms of human resources) and the information provided by them does not extend beyond their geographical position.

In contrast, species distribution modelling is a widely used method to investigate the potential occurrence and spread of species. Species distribution models (SDMs) are based on the relationship of a pool of georeferenced observations of a species occurrence (or abundance) with different environmental predictors across a determined geographical extent (Franklin, 2013). SDMs have been used in several fields of ecology such as research on invasive species (e.g., Dark, 2004), climate change impacts (e.g., Thuiller, Lavorel, Sykes, \& Araújo, 2006), conservation (e.g., Dubuis et al., 2011), and modelling of pest species distribution and spread (see Kehlenbeck et al., 2012 and Sutherst, 2013). Among these modelling techniques, the Maxent models (i.e., maximum entropy models) raised as a general-purpose machine learning method that allows modelling a species distribution using presence-only data (Phillips, Anderson, \& Schapire, 2006). However, although open-source and user-friendly tools are already available to follow this approach (e.g., Phillips, Anderson, Dudík, Schapire, \& Blair, 2017) and detailed presence/absence occurrence data are freely accessible from different resources (e.g., global species repositories), there is still a lack of detailed standalone distribution maps and species distribution models for $B$. oleae in the Iberian Peninsula.

The objectives of this work were (a) to provide an occurrencebased distribution map of B. oleae for the Iberian Peninsula (i.e., Spain and Portugal), and (b) to assess the climatic suitability across the same geographical extent based on bioclimatic drivers.

\section{MATERIALS AND METHODS}

The compilation of occurrence sites of B. oleae and O. europaea, the selection of bioclimatic drivers, and modelling processes were carried out using the environment for statistical computing R ( $\mathrm{R}$ Core Team, 2018).

\subsection{Occurrence-based distribution map}

Occurrence sites of $B$. oleae were collected through a bibliographic review that included scientific papers, Spanish government technical reports of $B$. oleae monitoring stations, the Global Biodiversity
Information Facility online database (GBIF, 2018), and personal observations. Analogously, occurrence sites for $O$. europaea were obtained from the former database only. The GBIF occurrence datasets (Bactrocera oleae (Rossi, 1790) in GBIF Secretariat (2017) and Olea europaea L. in GBIF Secretariat (2017)) were obtained using the gbif function of the rgbif\} package. The list of occurrence coordinates and corresponding references are provided in Table S1. A digital elevation model from Reuter, Nelson, and Jarvis (2007) was used to project the occurrences sites for the Iberian Peninsula.

\section{2 | Bioclimatic variables}

The bioclimatic variables used were obtained from the WorldClim database (Fick \& Hijmans, 2017). WorldClim is a gridded climate database that provides a set of bioclimatic variables derived from the monthly temperature and rainfall values representing annual trends, seasonality, and extreme or limiting environmental factors. The pool of 19 variables was downloaded at 2.5 minutes spatial resolution ( $4.5 \mathrm{~km}$ at the equator) and is described in Table 1. A driver selection was then carried out to avoid multicollinearity among the bioclimatic variables using the cor and findCorrelation functions of the $\{$ stats $\}$ and \{caret\} packages respectively. For this purpose, a pool of 1,000 random points across the Mediterranean basin extent was generated and those variables exceeding a threshold of 0.8 for the Pearson pairwise correlation were excluded for modelling.

TAB LE 1 Description of bioclimatic variables provided by the WorldClim database

\begin{tabular}{|c|c|}
\hline Code in database & Bioclimatic variable \\
\hline bio1 & Annual mean temperature \\
\hline bio2 & $\begin{array}{l}\text { Mean diurnal range (mean of monthly } \\
\text { [max temp - min temp]) }\end{array}$ \\
\hline bio3 & Isothermality (bio2/bio7) (×100) \\
\hline bio4 & $\begin{array}{l}\text { Temperature seasonality } \\
\quad(\text { standard deviation } \times 100)\end{array}$ \\
\hline bio5 & Max temperature of warmest month \\
\hline bio6 & Min temperature of coldest month \\
\hline bio7 & Temperature annual range (bio5-bio6) \\
\hline bio8 & Mean temperature of wettest quarter \\
\hline bio9 & Mean temperature of driest quarter \\
\hline bio10 & Mean temperature of warmest quarter \\
\hline bio11 & Mean temperature of coldest quarter \\
\hline bio12 & Annual precipitation \\
\hline bio13 & Precipitation of wettest month \\
\hline bio14 & Precipitation of driest month \\
\hline bio15 & Precipitation seasonality (coefficient of variation) \\
\hline bio16 & Precipitation of wettest quarter \\
\hline bio17 & Precipitation of driest quarter \\
\hline bio18 & Precipitation of warmest quarter \\
\hline bio19 & Precipitation of coldest quarter \\
\hline
\end{tabular}




\section{3 $\quad$ Species distribution modelling}

The model was developed using an $\mathrm{R}$ implementation of Maxent (Phillips et al., 2006), a machine-learning method that uses the principle of maximum entropy to approximate the unknown probability distribution of a species based on presence-only data (Phillips et al., 2006) using the maxent function of \{dismo\} package (Hijmans, Phillips, Leathwick, \& Elith, 2017). Although B. oleae is associated to the olive tree cultivation, the geographical extent of the selected bioclimatic drivers was focused on the Mediterranean basin $\left(15^{\circ} \mathrm{W}\right.$ $40^{\circ} \mathrm{E}, 27^{\circ} \mathrm{S}, 50^{\circ} \mathrm{N}$ ), the highest olive producing region worldwide (FAOSTAT, 2019) using the crop function of \{raster\} package (Figure S1).

The optimal model was selected following Muscarella et al. (2014) towards a balance of goodness-of-fit with model complexity and evaluation of models with spatially independent data. The \{ENMeval\} package allows creating data sets for $\mathrm{k}$-fold cross-validation using different methods for partitioning occurrence data, building a series of candidate models using the function ENMevaluate (calling the algorithm of \{maxnet\} package that uses \{glmnet\} for model fitting based on "Maxent" Java package, version 3.4.0), and provides evaluation metrics to select the optimal model settings. We used the "checkerboard1" method for partitioning occurrence data to build a series of 40 models corresponding to five combinations of feature classes (linear, quadratic, product, threshold, and hinge) and eight regularisation multipliers $(\beta)(0.5,1,1.5,2,2.5,3,3.5$, and 4). Duplicate presence points (i.e., occurrence points that fell in the same grid cell) were removed and 10,000 random background localities were used across the study extent (Figure S2). The occurrences records of $B$. oleae used in this work correspond to presence-only data thus the background data represent pseudo-absences towards AUC (area under the receiver operating characteristic curve) calculations (see below) (Barbet-Massin, Jiguet, Albert, \& Thuiller, 2012; Phillips \& Dudík, 2008).

The optimal model was assessed by selecting the one with the lowest AIC (Akaike Information Criterion). The AIC corrected for small samples sizes (AICC) reflects both model goodness-of-fit and complexity thus the model with the lowest AICc is considered the best model across the combinations of feature classes and regularisation multipliers (see Muscarella et al. (2014) for details). Once selected, the model was refitted using the optimal model tuning and the AUC was calculated. The AUC is a threshold independent measure of predictive accuracy based only on the ranking of locations (Merow, Smith, \& Silander, 2013) and ranges from 0.5 (i.e., random) for models with no predictive ability to 1.0 (i.e., perfect discrimination between suitable and unsuitable cells) for models with a perfect prediction. According to Swets (1988), a model with an AUC > 0.7 provides "useful" discrimination ability, >0.8 means "good" model performance, and >0.9 results in a "very good" model performance.

The bootstrapped standard error of AUC, its 95\% confidence interval, and the ROC (Receiver operating characteristic) curve were calculated following Steven and Phillips (2009) and using the $\{R O C R\}$ package (Sing, Sander, Beerenwinkel, \& Lengauer, 2005). Finally, the number of predicted values falling at each step of 0.1 within the range of predicted climatic suitability (i.e., 0.0-0.1, 0.1-0.2, 0.2-0.3, $0.3-0.4,0.4-0.5,0.5-0.6,0.6-0.7,0.7-0.8,0.8-0.9$, and 0.9-1.0) was calculated and 20 replicates of the predictions were run for plotting purposes. A response curve was fitted for each bioclimatic variable representing the average prediction for all data points that were used to fit the model. The response curves were calculated using the response function of \{dismo\} package. Finally, the chorological map of O. europaea of Caudullo, Welk, and San-Miguel-Ayanz (2017) (file Olea_europaea_europaea_plg_clip.shp) was used to graphically assess the amount of extended climatic suitability of $B$. oleae beyond the known distribution of the olive tree occurrence area in the Iberian Peninsula.

\section{3 | RESULTS}

\subsection{Occurrence-based distribution map}

The compilation of occurrence records of $B$. oleae resulted in a total of 762 records (Table S1) of which 219 presence records were used for training and 73 for testing after reducing the geographical extent to the target region (the Mediterranean basin). In the case of O. europaea, 37,556 records were downloaded from the GBIF database and used only for plotting purposes. The occurrence-based distribution map of $B$. oleae for the Iberian Peninsula is presented in Figure 1.

\section{2 | Bioclimatic variables}

The multicollinearity analysis resulted in the exclusion of the bioclimatic variables bio1, bio5, bio10, bio11, bio12, bio13, bio16, bio17, and bio18 (Figure 2) so that the mean diurnal range, isothermality,

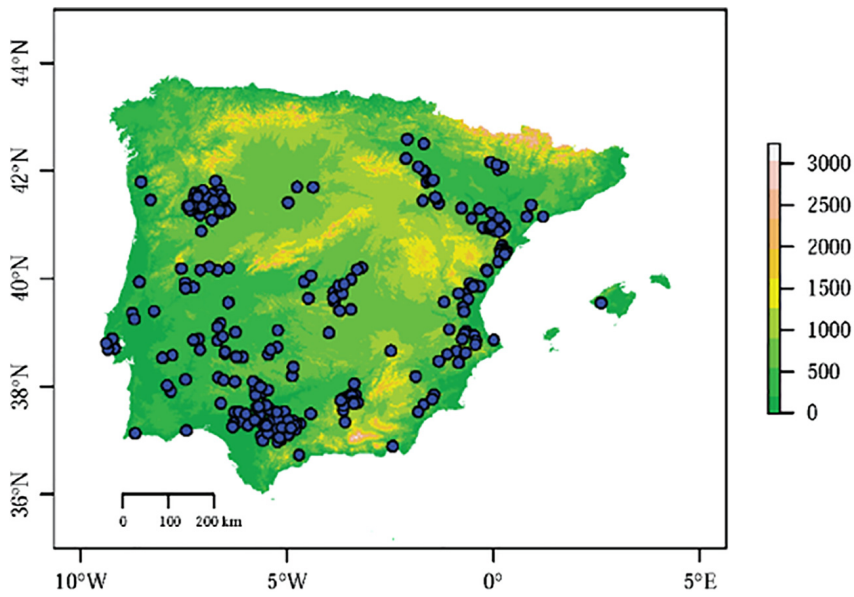

FIGURE 1 Occurrence-based distribution map of Bactrocera oleae throughout the Iberian Peninsula. Blue dots represent occurrence records projected on a digital elevation model. Altitude is expressed in metres $(m)$ 
temperature seasonality, minimum temperature of coldest month, temperature annual range, mean temperature of wettest quarter, mean temperature of driest quarter, precipitation of driest month, precipitation seasonality, and precipitation of coldest quarter were used as predictors for subsequent modelling purposes.

\section{3 $\quad$ Species distribution modelling}

Among the five feature combinations used to select the optimal model (L, LQ, LQH, LQHP, and LQHPT) and the eight regularisation multipliers (ranging from 0.5 to 4.0), the one that achieved the lowest AICc and a $\triangle A I C C=0$ was the linear and quadratic model (LQ) with a regularisation multiplier $(\beta)=0.5$, resulting in 17 parameters (Table S2). The LQ model gave an AUC $=0.923$ (Figure S3), with a bootstrapped standard error $=0.0146$, and a $95 \%$ confidence interval of $[0.894,0.951]$. In terms of prediction within the Iberian Peninsula $\left(10^{\circ} \mathrm{W}, 5^{\circ} \mathrm{E}, 35^{\circ} \mathrm{S}, 15^{\circ} \mathrm{N}\right)$ (Figure 3), $19.44 \%$ of cells fell within the [0.0, 0.1] interval of $\mathrm{p}$ (predicted climatic suitability), 9.21\% within [0.1, 0.2 ], 8.41\% within [0.2, 0.3], 8.59\% within [0.3, 0.4], 9.42\% within $[0.4,0.5], 9.81 \%$ within $[0.5,0.6], 9.68 \%$ within $[0.6,0.7], 8.97 \%$ within $[0.7,0.8], 8.15 \%$ within $[0.8,0.9]$, and $8.31 \%$ within $[0.9,0.10]$ (Figure S4). Among the selected bioclimatic variables, the drivers that contributed most to the Maxent model were the precipitation of coldest quarter, precipitation of driest month, and mean diurnal range whereas the mean temperature of the wettest quarter, the mean temperature of driest quarter, and isothermality were the less contributing variables (Table 2). The response curve for each bioclimatic variable is presented at Figure 4.

The average omission and predicted area for species, and the sensitivity versus specificity results (ROC) for the 20 replication runs of the optimal model are provided at the supplementary material as the Figure S5 and Figure S6 files, respectively.

Three potential distribution areas beyond the previously known occurrence range of the olive fruit fly were identified (Figure 5), each one representing a region where the olive tree is currently being cultivated: (a) the autonomous community of Galicia (Spain), (b) the Spanish and Portuguese sides of the International Douro Natural Park, and (c) the autonomous community of Castilla y León (Spain).

\section{4 | DISCUSSION}

In this work an occurrence-based distribution map of B. oleae for the Iberian Peninsula was built using different occurrence sources. The occurrence records were used subsequently to model the climatic suitability of $B$. oleae using a maximum entropy modelling approach and the AUC obtained (0.923) resulted in a very good model performance according to Swets (1988). Maxent models are commonly used to assess the probability of occurrence of a given species according to
FIGURE 2 Multicollinearity analysis of the pool of 19 bioclimatic variables available from WorldClim for the selected geographical extent of analysis (the Mediterranean basin: $15^{\circ} \mathrm{W}$, $\left.40^{\circ} \mathrm{E}, 27^{\circ} \mathrm{S}, 50^{\circ} \mathrm{N}\right)$. Pies represent the amount of Pearson correlation within each pair of variables. The description of bioclimatic variables is available at Table 1

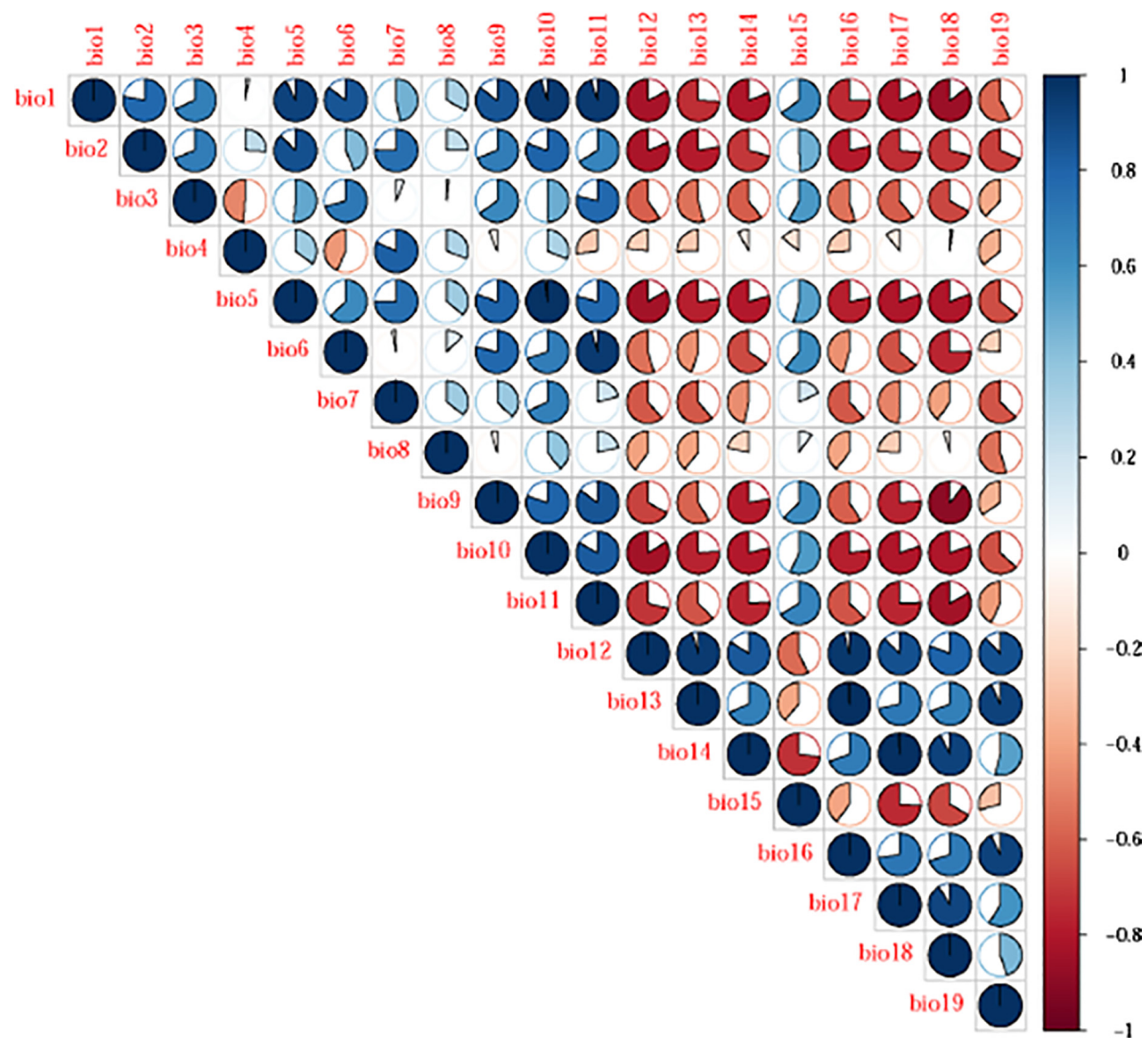




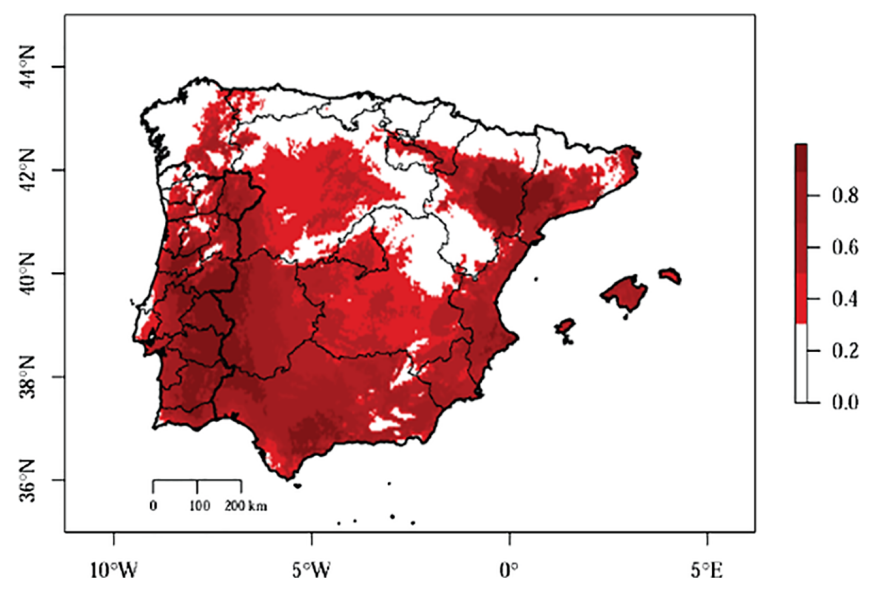

FIGURE 3 Mean of 20 Maxent prediction replicates using the linear and quadratic (LQ) model for the climatic suitability of Bactrocera oleae in the Iberian Peninsula. Colours have been chosen to allow risk assessment in terms of pest potential presence (i.e., reddish areas indicate higher climatic suitability)

TAB LE 2 Percent of contribution of each selected bioclimatic driver used to model the climatic suitability of Bactrocera oleae in the Iberian Peninsula

\begin{tabular}{|l|l|}
\hline Bioclimatic variable & Percent contribution \\
\hline Precipitation of coldest quarter & 22.20 \\
\hline $\begin{array}{l}\text { Precipitation of driest month } \\
\text { Mean diurnal range (mean of monthly [max } \\
\text { temp - min temp]) }\end{array}$ & 20.00 \\
\hline $\begin{array}{l}\text { Min temperature of coldest month } \\
\text { Temperature seasonality (standard } \\
\text { deviation } \times 100 \text { ) }\end{array}$ & 14.90 \\
\hline $\begin{array}{l}\text { Precipitation seasonality (coefficient of } \\
\text { variation) }\end{array}$ & 12.30 \\
\hline $\begin{array}{l}\text { Temperature annual range (max temperature } \\
\text { of warmest month - min temperature of }\end{array}$ & 9.10 \\
\hline $\begin{array}{l}\text { coldest month) } \\
\text { Mean temperature of wettest quarter }\end{array}$ & 1.60 \\
\hline Mean temperature of driest quarter & 0.50 \\
\hline $\begin{array}{l}\text { Isothermality (mean diurnal range/ } \\
\text { temperature annual range) } \times 100\end{array}$ & 0.20 \\
\hline
\end{tabular}

its potential distribution and based on the discrimination of suitable versus unsuitable areas for the species. In addition, niche-based models are usually projected on a target geographical extent, thus giving a theoretical area of predicted presence for the species (Phillips et al., 2006). However, several factors such as biotic interactions (Anderson, Peterson, \& Gómez-Laverde, 2002) and historical factors (Peterson, Soberón, \& Sánchez-Cordero, 1999) can lead a species to be unable to occupy a certain area even if favourable. In fact, in our case study, the "probability of occurrence" of B. oleae is determined a priori by the presence or absence of $O$. europaea thus we prefer to interpret our results strictly in terms of climatic suitability or potential distribution area instead of occurrence probability (see Yackulic et al., 2013).

The Maxent model prediction agrees in general with Müller, Dias, Gottschalk, Mello, and Nava (2019) and with the pattern found by Ponti, Gutierrez, Ruti, and Dell'Aquila (2014) through mechanistic physiologically-based demographic models (PBDMs) for the olive fruit fly abundance in the Mediterranean basin and extends its potential distribution area (i.e., areas with $p \geq 0.5$ ) to the autonomous communities of Galicia, Asturias, and Castilla y León, as well as to the whole Ebro river valley within Spain (Figures 3 and 4).

These results are of capital importance since Galicia (northwestern Spain) had recently emerged as a new olive-growing region housing two autochthonous cultivars (Brava and Mansa de Figueiredo) with potential relevant health benefits as a result of high concentration levels of phenolic compounds (Figueiredo-González et al., 2019; Reboredo-Rodríguez, González-Barreiro, Cancho-Grande, SimalGándara, \& Trujillo, 2018).

Analogously, the olive tree is one of the most extensively cultivated perennial species in the International Douro Natural Park. The Park encompass the border section of the Douro River, a deep, embedded valley with cliff margins that separate Portugal from Spain across more than $100 \mathrm{~km}$. The Spanish side of the Valley runs along the provinces of Zamora and Salamanca (Castilla y León) (Figure 4). In this region, the olive tree cultivation, with its own autochthonous cultivar (Zorzal) is of economic and social importance attending to its traditional use as excipient, medicinal properties, and ecotourism (including "olive-oil tourism") incoming (González, García-Barriuso, \& Amich, 2010; Marcos, 2010).

The autonomous community of Castilla y León houses $2 \%$ of the olive crop area of Spain (Muriel \& Marcos, 2012). Within this region, the olive tree cultivation in the province of Valladolid has been increasing during the last years. Cropping areas that formerly did not support the growing of $O$. europaea are nowadays being exploited taking advantage of increased temperatures as a result of climate change and irrigation (Moreno et al., 2005; Tanasijevic, Todorovic, Pereira, Pizzigalli, \& Lionello, 2014).

In terms of the predictive bioclimatic variables selected, our results are in line with the current knowledge on the life history of B. oleae and O. europaea. The olive tree is the most abundant perennial tree historically adapted to Mediterranean conditions (Loumou \& Giourga, 2003), i.e., a Csa-type climate according to the KöppenGeiger classification characterised by hot and dry summers and mild and moist winters (Peel, Grieser, Beck, Rudolf, \& Rubel, 2007). The drivers that most contributed to the model were the precipitation of the coldest quarter and the precipitation of driest month which suggest that the habitat requirements of $B$. oleae are directly or indirectly driven by boundary climatic conditions (i.e., limiting environmental factors for both the pest and the host species, O. europaea).

Although Podgornik, Vuk, Arbeiter, Hladnik, and Bandelj (2013) did not find a significant relationship between precipitation and trap captures in Slovenia, Yokoyama and Miller (2007) found in a series of laboratory and field studies at California that exposure to $5^{\circ} \mathrm{C}$ and $85 \% \mathrm{RH}$ caused $100 \%$ mortality of eggs and three larval instars. 

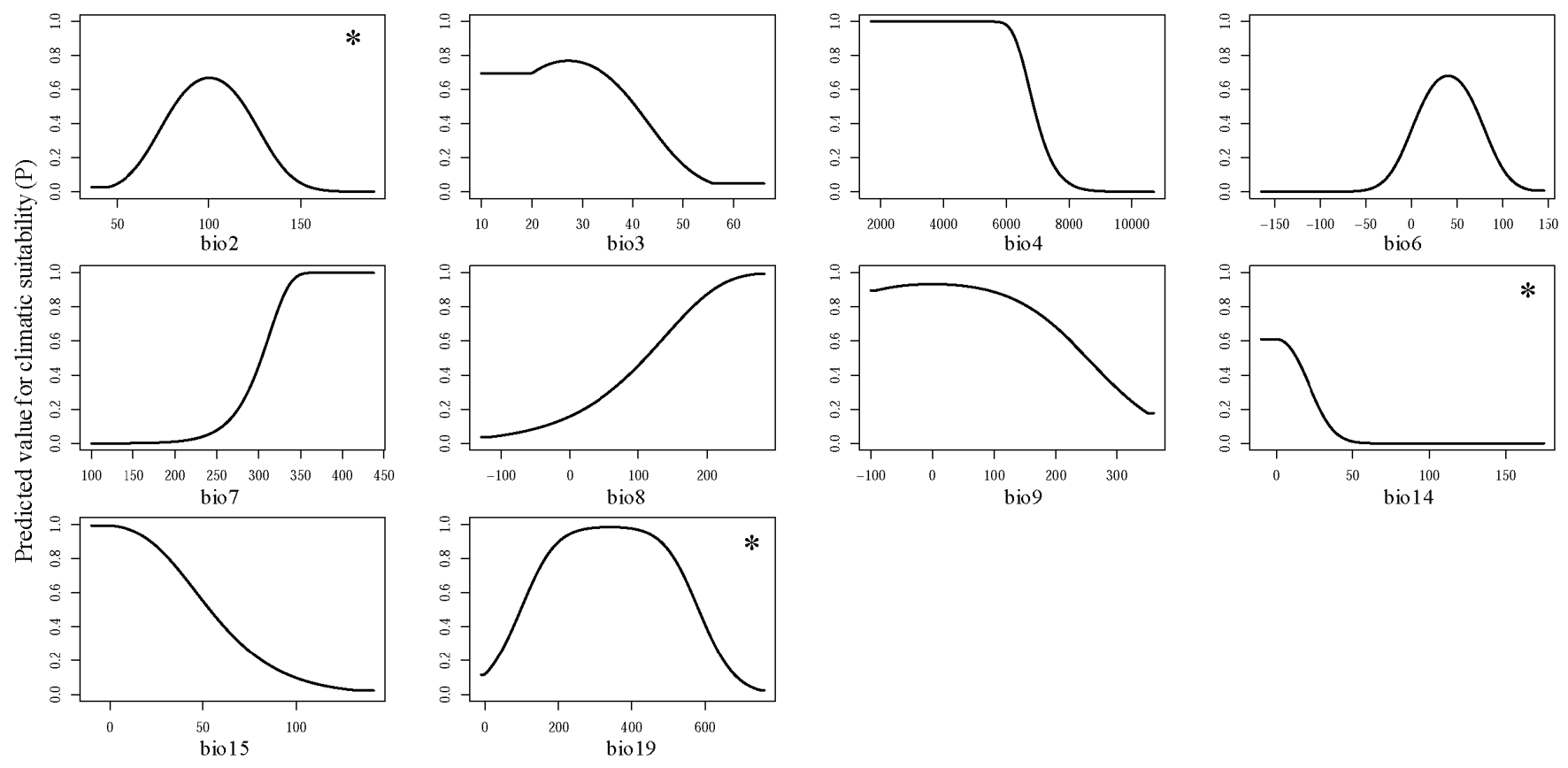

FIGURE 4 Response curve of each selected bioclimatic driver used to model the climatic suitability of Bactrocera oleae in the Iberian Peninsula. Asterisks indicate the three most contributing variables to the model: precipitation of coldest quarter (bio19), precipitation of driest month (bio14), and mean diurnal range (bio2). Codes of variables correspond to Table 1

Moreover, third instar larvae and 0-4 day-old pupae reached almost $100 \%$ of mortality after immersion in water saturated sand for 3 days. These agree with the predictions of our model since the climatic suitability for $\mathrm{B}$. oleae decreased at high values of the precipitation during the coldest quarter. In addition, the decreasing pattern in climatic suitability found for precipitation during the driest month agrees with the adaptation of $B$. oleae and its host to the hot and dry summers across the Mediterranean region. However, the survival of overwintering pupae of the olive fruit fly could be affected by soil moisture as Wang et al. (2013) found in California suggesting that mortality could result from pupae dehydration before the winter rains.

On the other hand, the following most contributing variable to the model prediction was the mean diurnal range of temperature. Almost all ecophysiological parameters of $B$. oleae are strongly affected by temperature (Baratella, Pucci, Paparatti, \& Speranza, 2017; Ordano et al., 2015; Pappas, Broufas, Koufali, Pieri, \& Koveos, 2011; Wang, Johnson, Daane, \& Nadel, 2009). For example, our model predicted a strong decrease in the climatic suitability for $B$. oleae at a mean diurnal range higher than $10^{\circ} \mathrm{C}$ and an optimal for the mean temperature of coldest month at $\sim 4.5^{\circ} \mathrm{C}$. Marchi, Guidotti, Ricciolini, and Petacchi (2016) found a consistent relationship between the degree of infestation and the temperature-based indices calculated for the previous period using decade-long agrometeorological time series whereas Gonçalves, Rodrigues, Pereira, Thistlewood, and Torres (2012) estimated that daily minimum temperature could explain the mortality of overwintering B. oleae in olive groves in the "Terra Quente" region of Trás-os-Montes (north-eastern Portugal).
Our Maxent model could reliably capture the bioclimatic information involved in the life-history of $B$. oleae using presence-only data. Of course, our modelling approach can be improved by considering different common model limitations such as sampling bias, representativeness of the selected geographical extent, optimal model selection (e.g., testing different methods of data partitioning, feature class combinations, and regularisation multipliers) as well as the consideration of further explanatory variables (e.g., pest dispersion ability, presence/ absence of olive trees, and the application of pesticides and management practices). Dealing with these issues implies a huge effort in terms of comprehensive sampling programs, bibliographic review and model development; however, despite some criticism to Maxent models (based on the narrow set of circumstances that allow for an unbiased equivalence between the logistic output and probability of occurrence (Yackulic et al., 2013), we showed how this approach can help identify potential risk areas of pest occurrence or colonisation with high economic implications. In any case, despite the hypothesis testing aim, model performance, and interpretation of a species distribution model, the process implicitly generates an occurrence-based distribution map for the target species which is itself a useful contribution.

In conclusion, the spread of the occurrence (actual or potential) of B. oleae, the amount of areas with predicted climatic suitability higher than 0.5 , and the extension of olive crop areas in the Iberian Peninsula make this region an excellent geographical area to investigate the processes involved in the potential dispersion/colonisation of $B$. oleae. For example, the increasing temperatures in response to climate change predicted by climate models (IPCC, 2014) makes mandatory to 


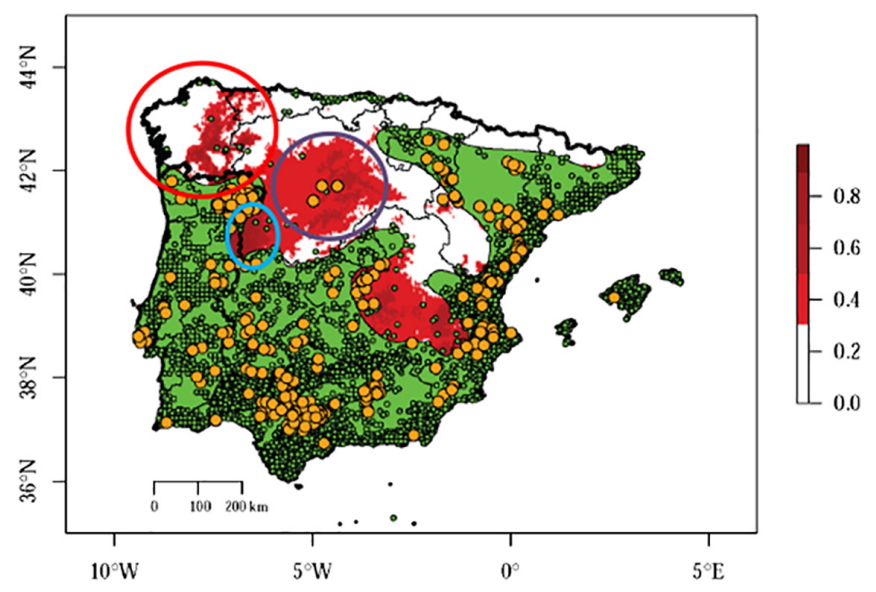

FIGURE 5 Extended distribution (mean of 20 Maxent prediction replicates using the linear and quadratic (LQ) model) of the climatic suitability ( $p$ ) of Bactrocera oleae in the Iberian Peninsula. Black thick lines represent country administrative limits. Black thin lines represent administrative limits of districts and autonomous communities for Portugal and Spain, respectively. Orange dots represent occurrence records of $B$. oleae, green dots represent occurrence records of Olea europaea, and the green area represents the current chorological map of O. europaea. The red, purple and blue circles encompass the autonomous community of Galicia, the central area of Castilla y León, and the Spanish side of the International Douro Natural Park. These areas of new olive cultivation with no previous capturing of the pest have been suggested by the model as suitable for pest establishment. Reddish areas indicate higher climatic suitability

study the effect of climate change on the relationships between the olive tree and its obligate pest $B$. oleae.

Although using a Maxent approach to model shifts in a species distribution (e.g., anticipation of pest invasion purposes) as a result of climate change (e.g., under different representative concentration pathways [RCPs], i.e., different greenhouse gas concentration trajectories adopted by the IPCC) could be tempting, different aspects such as biotic interactions, evolutionary change, dispersal ability, and emergence of new fundamental niches should be taken into account beyond regarding only climate variables (Guisan, Petitpierre, Broennimann, Daehler, \& Kueffer, 2014; Pearson \& Dawson, 2003; Veloz et al., 2012). For this, powerful individual-based approaches such as climate envelope and physiologically based demographic models (PBDM) (Gutierrez, 2009; Gutierrez, Ponti, d'Oultremont, \& Ellis, 2008) and recent eco-evolutionary models (Grimm, Ayllón, \& Railsback, 2017; Moya-Laraño et al., 2014) have been used and rising respectively and could help to deal with this task in the near future. We hope this work would represent a stimulus for further research towards a deeper knowledge of a biological system as important as the olive grove agroecosystem.

\section{AUTHOR CONTRIBUTIONS}

J. B. -M., P. B., and J. A. P. conceived the idea, J. B. -M. developed the model, and J. B. -M, P. B., J. A. P., and S. A. P. S. contributed to writing the paper.

\section{ACKNOWLEDGEMENTS}

The authors are grateful to the Foundation for Science and Technology (FCT, Portugal) for financial support by national funds FCT/MCTES to CIMO (UIDB/00690/2020), and to the project POCI-01-0145FEDER-031133, "MicOlives - Exploiting plant induced resistance by beneficial fungi as a new sustainable approach to olive crop protection".

\section{CONFLICT OF INTEREST}

The authors have no conflicts of interest to declare.

\section{ORCID}

Jacinto Benhadi-Marín (D) https://orcid.org/0000-0002-9804-4145

\section{REFERENCES}

Anderson, R. P., Peterson, A. T., \& Gómez-Laverde, M. (2002). Using niche-based GIS modeling to test geographic predictions of competitive exclusion and competitive release in South American pocket mice. Oikos, 98, 3-16.

Bactrocera oleae (Rossi, 1790) in GBIF Secretariat. (2017). GBIF Backbone Taxonomy. Checklist dataset https://doi.org/10.15468/39omei.

Baratella, V., Pucci, C., Paparatti, B., \& Speranza, S. (2017). Response of Bactrocera oleae to different photoperiods and temperatures using a novel method for continuous laboratory rearing. Biological Control, 110, 79-88.

Barbet-Massin, M., Jiguet, F., Albert, C. H., \& Thuiller, W. (2012). Selecting pseudo-absences for species distribution models: How, where and how many? Methods in Ecology and Evolution, 3, 327-338.

Boccaccio, L., \& Petacchi, R. (2009). Landscape effects on the complex of Bactrocera oleae parasitoids and implications for conservation biological control. BioControl, 54, 607-616.

Caudullo, G., Welk, E., \& San-Miguel-Ayanz, J. (2017). Chorological maps for the main European woody species. Data in Brief, 12, 662-666.

$R$ Core Team. (2018). $R$ : A language and environment for statistical computing. Vienna, Austria: R Foundation for Statistical Computing Available from: http://www.R-project.org

Dark, S. J. (2004). The biogeography of invasive alien plants in California: An application of GIS and spatial regression analysis. Diversity and Distributions, 10, 1-9.

Dubuis, A., Pottier, J., Rion, V., Pellissier, L., Theurillat, J. P., \& Guisan, A. (2011). Predicting spatial patterns of plant species richness: A comparison of direct macroecological and species stacking modelling approaches. Diversity and Distributions, 17, 1122-1131.

FAOSTAT. (2019). FAOSTAT Statistics Database. Rome, Italy: Food and Agriculture Organization of the United Nations (FAO). Available from: http://www.fao.org/faostat/en/\#home

Fick, S. E., \& Hijmans, R. J. (2017). Worldclim 2: New 1-km spatial resolution climate surfaces for global land areas. International Journal of Climatology. Available from: http://worldclim.org/version2, 37, 4302-4315.

Figueiredo-González, M., Reboredo-Rodríguez, P., González-Barreiro, C., Carrasco-Pancorbo, A., Cancho-Grande, B., \& Simal-Gándara, J. (2019). The involvement of phenolic-rich extracts from Galician autochthonous extra-virgin olive oils against the $\alpha$-glucosidase and $\alpha$-amylase inhibition. Food Research International, 116, 447-454.

Franklin, J. (2013). Species distribution models in conservation biogeography: Developments and challenges. Diversity and Distributions, 19, 1217-1223.

GBIF. (2018). The global biodiversity information facility. What is GBIF? Available from: https://www.gbif.org/what-is-gbif.

Gonçalves, F. M., Rodrigues, M. C., Pereira, J. A., Thistlewood, H., \& Torres, L. M. (2012). Natural mortality of immature stages of Bactrocera oleae (Diptera: Tephritidae) in traditional olive groves from 
North-Eastern Portugal. Biocontrol Science and Technology, 22, 837-854.

González, J. A., García-Barriuso, M., \& Amich, F. (2010). Ethnobotanical study of medicinal plants traditionally used in the Arribes del Duero, western Spain. Journal of Ethnopharmacology, 131(2), 343-355.

Grimm, V., Ayllón, D., \& Railsback, S. F. (2017). Next-generation individualbased models integrate biodiversity and ecosystems: Yes we can, and yes we must. Ecosystems, 20, 229-236.

Guisan, A., Petitpierre, B., Broennimann, O., Daehler, C., \& Kueffer, C. (2014). Unifying niche shift studies: Insights from biological invasions. Trends in Ecology \& Evolution, 29(5), 260-269.

Gutierrez, A. P., Ponti, L., \& Cossu, Q. A. (2009). Effects of climate warming on olive and olive fly (Bactrocera oleae [Gmelin]) in California and Italy. Climatic Change, 95, 95-217.

Gutierrez, A. P., Ponti, L., d'Oultremont, T., \& Ellis, C. K. (2008). Climate change effects on poikilotherm tritrophic interactions. Climatic Change, 87(Suppl 1), S167-S192.

Haber, G., \& Mifsud, D. (2007). Pests and diseases associated with olive trees in the Maltese islands (Central Mediterranean). The Central Mediterranean Naturalist, 4(3), 143-161.

Haniotakis, G. E. (2003). Olive pest control: Present status and prospects. In Proceedings of the IOBC/WPRS Conference on Integrated Protections of Olive Crops, Chania, Crete.

Hijmans, R.J., Phillips, S., Leathwick, J., \& Elith, J. (2017). dismo: Species distribution Modeling. $R$ package, version 1.1-4. Available from: https://CRAN.R-project.org/package=dismo

IPCC (2014). Climate change 2014: Synthesis report. In R. K. Pachauri \& L. Meyer (Eds.), Contribution of Working Groups I, II and III to the Fifth Assessment Report of the Intergovernmental Panel on Climate Change. Core writing Team (p. 151). Geneva, Switzerland: IPCC.

Kehlenbeck, H., Robinet, C., van der Werf, W., Kriticos, D., Reynaud, P., \& Baker, R. (2012). Modelling and mapping spread in pest risk analysis: A generic approach. OEPP/EPPO Bulletin, 42(1), 74-80.

Loumou, A., \& Giourga, C. (2003). Olive groves: "The life and identity of the Mediterranean". Agriculture and Human Values, 20, 87-95.

Marchi, S., Guidotti, D., Ricciolini, M., \& Petacchi, R. (2016). Towards understanding temporal and spatial dynamics of Bactrocera oleae (Rossi) infestations using decade-long agrometeorological time series. International Journal of Biometeorology, 60, 1681-1694.

Marcos, D. (2010). Arribes del Duero: Olivicultura al límite. www. variedadesdeolivo.com. Boletín $n^{\circ}$ 7. Available from: http://www. variedadesdeolivo.com/reportajes /7\%20Arribes\%20del\%20Duero,\% 20olivicultura\%20al\%20limite.pdf. 16 pp.

Merow, C., Smith, M. J., \& Silander, J. A. (2013). A practical guide to Maxent for modeling species' distributions: What it does, and why inputs and settings matter. Ecography, 36, 1058-1069.

Moreno, J. M., Aguiló, E., Alonso, S., Álvarez-Cobelas, M., Anadón, R., Ballester, F., ... Zazo, C. (2005). A preliminary assessment of the impacts in Spain due to the effects of climate change. In ECCE PROJECT - Final Report (p. 786). Spain: Ministerio del Medio AmbienteUniversidad de Castilla la Mancha.

Moya-Laraño, J., Bilbao-Castro, J. R., Barrionuevo, G., Ruiz-Lupión, D., Casado, L. G., Montserrat, M., ... Magalhães, S. (2014). Ecoevolutionary spatial dynamics: Rapid evolution and isolation explain food web persistence. In J. Moya-Laraño, J. Rowntree, \& G. Woodward (Eds.), Advances in ecological research, Vol. 50 (pp. 75-143). Oxford: Oxford Academic Press.

Müller, F. A., Dias, N. P., Gottschalk, M. S., Mello, F. R., \& Nava, D. E. (2019). Potential distribution of Bactrocera oleae and the parasitoids Fopius arisanus and Psyttalia concolor, aiming at classical biological control. Biological Control, 132, 144-151.

Muriel, C. \& Marcos, D. (2012). El cultivo del olivo en Valladolid. www.variedadesdeolivo.com. Available from: http://www.variedadesdeolivo. com/reportajes /El\%20olivo\%20en\%20Valladolid.pdf. Reportaje $\mathrm{n}^{\circ}$ $30.8 \mathrm{pp}$.
Muscarella, R., Galante, P. J., Soley-Guardia, M., Boria, R. A., Kass, J. M., Uriarte, M., \& Anderson, R. P. (2014). ENMeval: An R package for conducting spatially independent evaluations and estimating optimal model complexity for Maxent ecological niche models. Methods in Ecology and Evolution, 5, 1198-1205.

Olea europaea L. in GBIF Secretariat. (2017). GBIF Backbone Taxonomy. Checklist dataset https://doi.org/10.15468/39omei

Ordano, M., Engelhard, I., Rempoulakis, P., Nemny-Lavy, E., Blum, M., Yasin, S., ... Nestel, D. (2015). Olive fruit fly (Bactrocera oleae) population dynamics in the eastern Mediterranean: Influence of exogenous uncertainty on a monophagous frugivorous insect. PLoS One, 10(5), e0127798.

Pappas, M. L., Broufas, G. D., Koufali, N., Pieri, P., \& Koveos, D. S. (2011). Effect of heat stress on survival and reproduction of the olive fruit fly Bactocera (Dacus) oleae. Journal of Applied Entomology, 135, 359-3366.

Pearson, R. G., \& Dawson, T. P. (2003). Predicting the impacts of climate change on the distribution of species: Are bioclimate envelope models useful? Global Ecology and Biogeography, 12, 361-371.

Peel, M. C., Grieser, J., Beck, C., Rudolf, B., \& Rubel, F. (2007). Updated world map of the Köppen-Geiger climate classification. Meteorologische Zeitschrift, 15, 259-263.

Pereira, J. A., Alves, M. R., Casal, S., \& Oliveira, M. B. P. P. (2004). Effect of olive fruit fly infestation on the quality of olive oil from cultivars Cobrancosa, Madural and Verdeal Transmontana. Italian Journal of Food Science, 16(3), 355-365.

Peterson, A. T., Soberón, J., \& Sánchez-Cordero, V. (1999). Conservatism of ecological niches in evolutionary time. Science, 285, 1265-1267.

Phillips, S. J., Anderson, R. P., Dudík, M., Schapire, R. E., \& Blair, M. E. (2017). Opening the black box: An open-source release of Maxent. Ecography, 40, 887-893.

Phillips, S. J., Anderson, R. P., \& Schapire, R. E. (2006). Maximum entropy modeling of species geographic distributions. Ecological Modelling, 190, 231-259.

Phillips, S. J., \& Dudík, M. (2008). Modeling of species distributions with Maxent: New extensions and a comprehensive evaluation. Ecography, 31, 161-175.

Podgornik, M., Vuk, I., Arbeiter, A., Hladnik, M., \& Bandelj, D. (2013). Population fluctuation of adult males of the olive fruit fly Bactrocera oleae (Rossi) analysis in olive orchards in relation to abiotic factors. Entomology News, 123, 15-25.

Ponti, L., Gutierrez, A. P., Ruti, P. M., \& Dell'Aquila, A. (2014). Fine-scale ecological and economic assessment of climate change on olive in the Mediterranean Basin reveals winners and losers. Proceedings of the National Academy of Sciences of the United States of America, 111(15), 5598-5603.

Reboredo-Rodríguez, P., González-Barreiro, C., Cancho-Grande, B., SimalGándara, J., \& Trujillo, I. (2018). Genotypic and phenotypic identification of olive cultivars from North-Western Spain and characterization of their extra virgin olive oils in terms of fatty acid composition and minor compounds. Scientia Horticulturae, 232, 269-279.

Reuter, H. I., Nelson, A., \& Jarvis, A. (2007). An evaluation of void filling interpolation methods for SRTM data. International Journal of Geographic Information Science, 21(9), 983-1008.

Sing, T., Sander, O., Beerenwinkel, N., \& Lengauer, T. (2005). ROCR: Visualizing classifier performance in R. Bioinformatics, 21(20), 3940-3941.

Steven, J., \& Phillips, S. J. (2009). A brief tutorial on Maxent. Network of conservation educators and practitioners, Center for Biodiversity and Conservation, American Museum of Natural History. Lessons in Conservation, 3, 108-135.

Sutherst, R. W. (2013). Pest species distribution modelling: Origins and lessons from history. Biological Invasions, 16, 239-256.

Swets, J. A. (1988). Measuring the accuracy of diagnostic systems. Science, 240, 1285-1293.

Tanasijevic, L., Todorovic, M., Pereira, L. S., Pizzigalli, C., \& Lionello, P. (2014). Impacts of climate change on olive crop evapotranspiration 
and irrigation requirements in the Mediterranean region. Agricultural Water Management, 144, 54-68.

Thuiller, W., Lavorel, S., Sykes, M. T., \& Araújo, M. B. (2006). Using niche-based modelling to assess the impact of climate change on tree functional diversity in Europe. Diversity and Distributions, 12 , 49-60.

Veloz, S. D., Williams, J. W., Blois, J. L., He, F., Otto-Bliesner, B., \& Liu, Z. (2012). No-analog climates and shifting realized niches during the late quaternary: Implications for $21^{\text {st }}$-century predictions by species distribution models. Global Change Biology, 18, 1698-1713.

Wang, X. G., Johnson, M. W., Daane, K. M., \& Nadel, H. (2009). High summer temperatures affect the survival and reproduction of olive fruit fly (Diptera: Tephritidae). Environmental Entomology, 38(5), 1496-1504.

Wang, X. G., Levy, K., Nadel, H., Johnson, M. W., Blanchet, A., Argov, Y., ... Daane, K. M. (2013). Overwintering survival of olive fruit fly (Diptera: Tephritidae) and two introduced parasitoids in California. Environmental Entomology, 42(3), 467-476.

Yackulic, C. B., Chandler, R., Zipkin, E. F., Royle, J. A., Nichols, J. D., Campbell Grant, E. H., \& Veran, S. (2013). Presence-only modelling using MAXENT: When can we trust the inferences? Methods in Ecology and Evolution, 4, 236-243.

Yokoyama, V. Y., \& Miller, G. T. (2007). Olive fruit fly biology and cultural control practices in California. International Organization for Biological Control Western Palearctic Section Bulletin, 30, 263-269.

\section{SUPPORTING INFORMATION}

Additional supporting information may be found online in the Supporting Information section at the end of this article.

How to cite this article: Benhadi-Marín J, Santos SA, Baptista P, Pereira JA. Distribution of Bactrocera oleae (Rossi, 1790) throughout the Iberian Peninsula based on a maximum entropy modelling approach. Ann Appl Biol. 2020;177:

112-120. https://doi.org/10.1111/aab.12584 